\title{
Extra genital HPV-6
}

\section{Aicha Nassiri', Niema Aqil', Hanane Baybay ${ }^{1}$, Fatima Zahra Mernissi', Omar Amrani Souhli ${ }^{2}$, Mustapha Ahssaini' ${ }^{2}$, Jallal Eddine El Ammari' ${ }^{2}$, Fadl Mohamed Tazi $^{2}$, Mohamed Jamal EI Fassi ${ }^{2}$, Moulay Hassan Farih², Reda Chadli ${ }^{3}$, Aya Oufkir ${ }^{3}$}

\author{
${ }^{1}$ Departement of Dermatology, Hassan II Hospital, Fez, Morroco, ${ }^{2}$ Departement of Urology, Hassan II Hospital, Fez, \\ Morroco, ${ }^{3}$ Departement of Plastic Surgery, Hassan II Hospital, Fez, Morroco
}

Corresponding author: Dr. Aicha Nassiri, e-mail: aichanassiri6@gmail.com

\begin{abstract}
The buschke lowenstein tumor is a rare sexually transmitted disease. We report a case of a buschke lowenstein disease sitting onthe neck, the back in addition to genital area. A 58 years old patient, without any significant pathological antecedents, presented for more than 3 years genital tumors gradually getting bigger. Dermatological examination found several ulcerated, exophytic, cauliflower tumors taking all the urogenital area, two tumors setting in the neck and one another on the back. Cytological sampling was performed, and the search for HPV returned positive. Other serologies have returned negative. The patient was subsequently treated by the urologist and plastician team. Complete exeresis was performed. An anatomopathological study was done which confirmed the diagnosis. HPV typing was done and confirmed HPV 6. The patient has evolved well and presented no complication. Buschke-lowenstein disease is a curable sexually transmitted urogenital disease. We report for the an unusual three location of this disease, which can shed light on the mode of transmission.
\end{abstract}

Key words: Buschke lowenstein, Condyloma acuminate, Extra genital, HPV 6

\section{INTRODUCTION}

The buschke lowenstein tumor, also called the giant condyloma, is a rare sexually transmitted disease [1]. Men are affected, but case reports of women and children have been reported [2].

Extra genital cases are very rare but not impossible. We report a case of a buschke lowenstein disease sitting onthe neck, the back in addition to genital area.

\section{CASE REPORT}

A 58 years old patient, married, without any significant pathological antecedents, presented for more than 3 years genital tumors gradually getting bigger. And soon, tumors also appeared in the neck and back. On examination the patient was conscious, hemodynamically stable. Dermatological examination found several ulcerated, exophytic, cauliflower tumors taking all the urogenital area, two tumors setting in the neck and one another on the back (Fig. 1).

Cytological sampling was performed, and the search for HPV returned positive.

Other serologies have returned negative.

The patient was subsequently treated by the urologist and plastician team. Complete exeresis was performed. An anatomopathological study was done which confirmed the diagnosis. HPV typing was done and confirmed HPV 6 (Fig. 2).

The follow-up didn't reveal any complications (Fig. 3).

Prior to the study, patient gave written consent to the examination and biopsy after having been informed about the procedure.

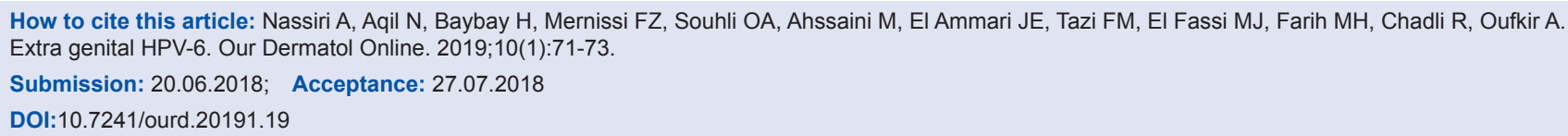




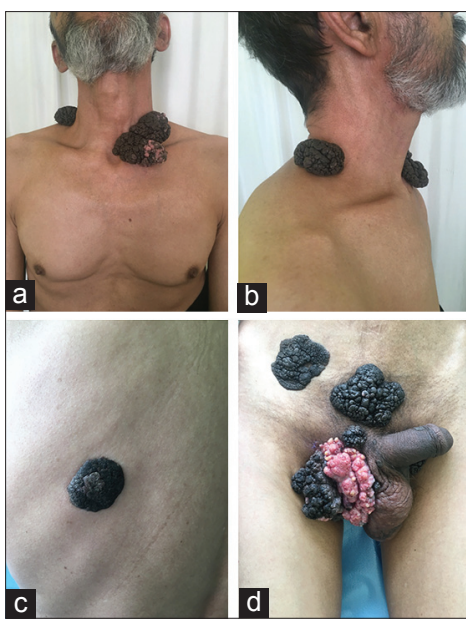

Figure 1a-d: Cawliflower tumors.

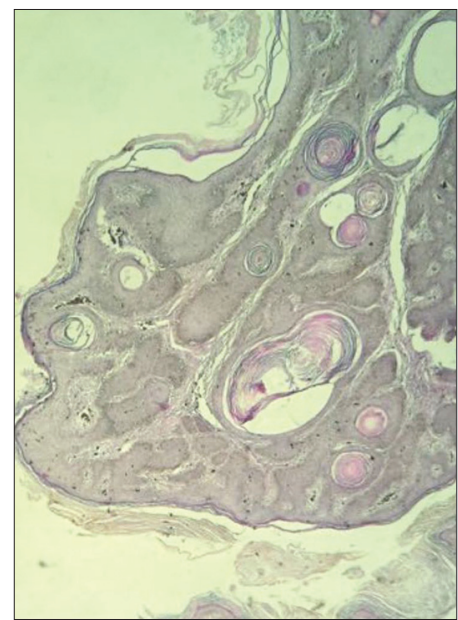

Figure 2: Histopathology: Geant condyloma acuminata.
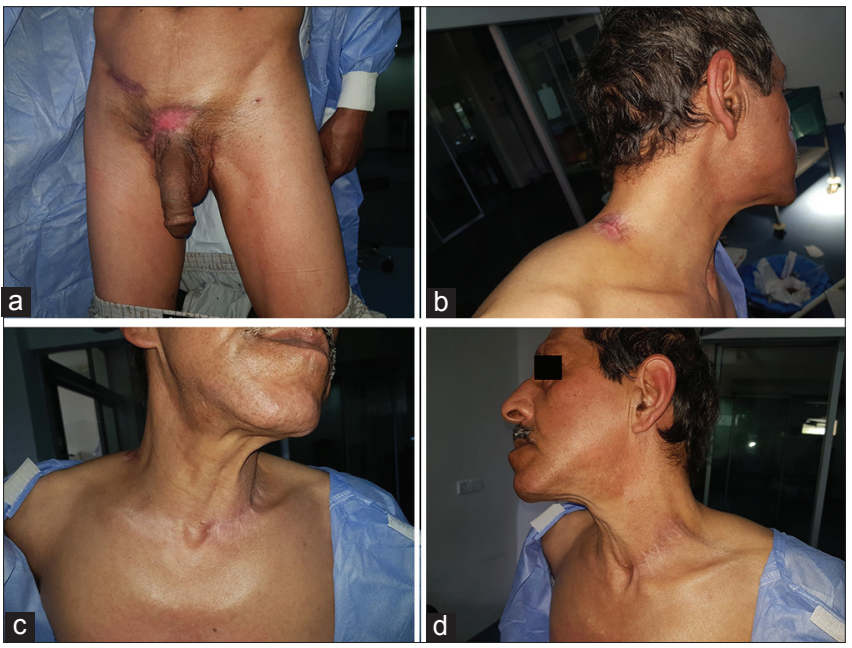

Figure 3a-d: Three months after surgery.

\section{DISCUSSION}

Buschke lowenstein disease, described for the first time by ludwig loweinstein and abraham buschke as a malignant acuminous condyloma [3]. Subsequently, it was classified as a verrucous carcinoma [4]. It is a rare enough sexually transmitted disease affecting mainly men between the age of 40 and 60 years as in our patient $[5,6]$.

This tumor usually affects the ano-genital area, the inner sides of the thighs.

Anogenital giant condyloma usually appears in young patients as a slow-growing mass, present for months or years before the patient seeks medical attention. Its development and growth rate have been associated with impaired immunity, particularly that caused by human immunodeficiency virus infection, as well as with pregnancy and multiple comorbidities

Viral cytopathic changes and HPV types 6 and 11 are consistently identified in cases of giant condyloma, whereas this association is less consistent in verrucous carcinoma [7]. In addition, giant condyloma lacks the broadbased appearance and altered keratinocyte differentiation of verrucous carcinomas $[8,9]$. Nonetheless, others believe that both lesions represent the same entity, given that giant condyloma can sometimes be locally destructive [10].

The particularity of our observation lies in the extra-genital location, and more particularly in the neck and back. Our patients share clinical and pathologic features typically seen in anogenital giant condyloma.

The clincal presnetation is very classic, but when found on extra genital area, some questions must be asked [7]. For many reason we sought to make HPV typing trying to confirm the nature of the extra genital tumors, and concluded that the same HPV was responsible for the tumors on both locations. A previously reported case of cervical giant condyloma also occurred in a young woman during pregnancy [10].

This could be explained by the manuportage, and the transmission of HPV by scratching.

Several therapeutic eventualities exist, the gold standard is surgery.

Other treatments such as Photodynamic therapy, CO2 laser, podophyllin, methotrexate and cryotherapy are reserved for small tumors and reccurent lesions. 


\section{CONCLUSION}

Buschke-lowenstein disease is a curable sexually transmitted urogenital disease. We report for the an unusual three location of this disease, which can shed light on the mode of transmission.

\section{CONSENT}

The examination of the patient was conducted according to the Declaration of Helsinki principles.

\section{REFERENCES}

1. Spînu D, Rãdulescu $A$, Bratu $O$, Checheriåã $I A$, Ranetti $A E$, Mischianu D. Giant Condyloma Acuminatum - Buschke-Löwenstein Disease - a Literature Review. Chirurgia. 2014;109:445-50,

2. Gole GN, Shekhar TY, Gole SG, Prabhala S. Successful treatment of Buschke-Löwenstein tumor by surgical excision alone. J Cutan Aesthet Surg. 2010;3:174-6.

3. Steffen C. The men behind the eponym - Abraham Buschke and Ludwig Lowenstein: giant condyloma (Buschke-Loewenstein). Am
J Dermatopathol. 2006;28:526-36.

4. Singh P, Nathani D, Ranjan S, Issar R. A Giant Cutaneous Horn Projecting from Verrucous Carcinoma of Buccal Mucosa: A Rare Case Report. J Clin Diagn Res. 2017;11:ZD04-5.

5. Qarro A, Ait Ali A, Choho A, Alkandry S, Borki K. Ann Chirur. 2005;130: 96-100.

6. Ottavioli A, Campana F, Catherine JH, Massereau E, Del Grande J, Ordioni U. [Proliferative verrucous leukoplakia: Three cases and literature review]. Ann Dermatol Venereol. 2016;143:187-96.

7. Parra-Herran C, Herfs M, Doria M, Crum CP, Nucci MR. Giant Condyloma of the Cervix An Uncommon Entity Associated With Low-risk Human Papilloma Virus Infection. Am J Surg Pathol. 2013;37:33-4.

8. Crum Christopher P, Nucci Marisa R, Lee Kenneth R. Diagnostic Gynecologic and Obstetric Pathology. $2^{\text {nd }}$ ed. Philadelphia, PA: Elsevier; 2011:201-203. 9. Trombetta.

9. Shenoy S. Perianal giant condyloma acuminatum (BuschkeLöwenstein tumor). Skinmed. 2014;12:114-5.

10. Longacre TA, Kong CS, Welton ML. Diagnostic problems in anal pathology. Adv Anat Pathol. 2008;15:263-78.

Copyright byAicha Nassiri, et al. This is an open-access article distributed under the terms of the Creative Commons Attribution License, which permits unrestricted use, distribution, and reproduction in any medium, provided the original author and source are credited.

Source of Support: Nil, Conflict of Interest: None declared. 